\title{
Costal Cartilages Do Not Overgrow in Patients with Pectus Excavatum
}

\author{
Vlad-Laurentiu David ${ }^{a}$ Simona Cerbu ${ }^{d}$ Horia Haragus ${ }^{b}$ Marius-Calin Popoiu ${ }^{a}$ \\ Corina-Maria Stanciulescu ${ }^{a}$ Gabriel Cozma ${ }^{c}$ Ovidiu Burlacu ${ }^{c}$ Eugen-Sorin Boia ${ }^{a}$ \\ ${ }^{a}$ Department of Pediatric Surgery, ${ }^{b}$ First Clinic of Orthopedics and Trauma and 'Department of Thoracic Surgery, 'Victor \\ Babes' University of Medicine and Pharmacy, and 'Department of Imagistics, Emergency Children's Hospital 'Louis \\ Turcanu', Timisoara, Romania
}

\section{Key Words}

Pectus excavatum - Costal cartilage · Overgrowth · Cartilage length

\begin{abstract}
Objective: The purpose of this study was to determine whether or not patients with pectus excavatum (PE) exhibit costal cartilage overgrowth compared to normal subjects. Materials and Methods: The computed tomography acquisitions of 32 patients with PE and 35 normal controls were analyzed. On axial images the length of the 4th-7th costal cartilages was measured to calculate the Haller index. The ratio between the length of the cartilages and the median of the transverse and longitudinal thorax diameters were recorded to account for anatomical variability. The length of the cartilages was compared between the PE and control subjects using the independent-samples $t$ test. For patients with asymmetric PE the length of the 4th-7th costal cartilages was compared between the rotated and nonrotated sides. Results: The mean transverse and coronal thorax diameters were $233.29 \pm 24.47$ and $231.69 \pm 22.47 \mathrm{~mm}$ for $\mathrm{PE}$ patients and $252.67 \pm 37.25$ and $238.64 \pm 27.40 \mathrm{~mm}$ for controls, respectively, with no significant differences between the two groups ( $p=0.816$ and 0.145 ). The mean sagittal di-
\end{abstract}

ameter $(59.30 \pm 14.21 \mathrm{~mm})$ and Haller index $(4.02 \pm 1.34)$ in the PE group were significantly different from the controls $(107.34 \pm 19.59$ and $2.2 \pm 0.54 \mathrm{~mm}$, respectively; $p=0.00)$. Actual and relative lengths of costal cartilages were similar in both PE subjects and controls for all 4 costal cartilages measured. In subjects with asymmetric $P E$, both relative and absolute costal cartilage lengths were similar on the rotated and nonrotated side. Conclusions: The length of the 4th, 5th, 6th and 7th costal cartilages was similar in PE patients and the control subjects. These was also similar between the rotated and nonrotated sides of the sternum in patients with asymmetric $P E$.

ㄷ) 2016 S. Karger AG, Basel

\section{Introduction}

The etiology of anterior chest wall deformities so far remains elusive. Overgrowth of the costal cartilages is the most popular etiopathogenic theory. It is based on studies demonstrating an intrinsic disturbance of the costal cartilages in patients with pectus excavatum (PE) [1-3]. Nevertheless, a direct link between the histologic disturbances of the costal cartilages and the overgrowth of the cartilages has not been demonstrated [2]. However, it has been

\begin{tabular}{ll}
\hline KARGER & $\begin{array}{l}\text { ( ) 2016 S. Karger AG, Basel } \\
1011-7571 / 16 / 0256-0533 \$ 39.50 / 0 \quad \text { Karger }\end{array}$ \\
$\begin{array}{l}\text { E-Mail karger@karger.com } \\
\text { www.karger.com/mpp }\end{array}$ & $\begin{array}{l}\text { Thisis an Open Access article licensed under the terms of the } \\
\text { Creative Commons Attribution-NonCommercial 3.0 Un- } \\
\text { ported license (CC BY-NC) (www.karger.com/OA-license), } \\
\text { applicable to the online version of the article only. Distribu- } \\
\text { tion permitted for non-commercial purposes only. }\end{array}$
\end{tabular}

Eugen-Sorin Boia

Department of Pediatric Surgery, 'Victor Babes' University of Medicine and Pharmacy 2 Eftimie Murgu

RO-300041 Timisoara (Romania)

E-Mail chirpedmin@gmail.com 
Fig. 1. Measurement of the length of the costal cartilages and the transverse and sagittal diameters in PE patients (a) and controls (b). c Measurement of the height of the thorax.
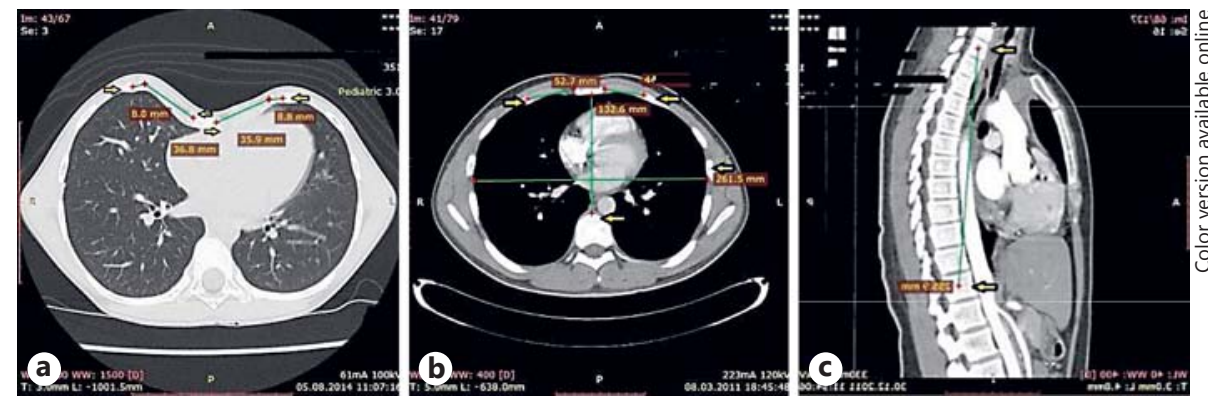

postulated that the disturbance of the costal cartilage leads to reduced strength of the costal cartilage and not to overgrowth, and therefore the inward bending of the sternum is caused by diaphragm traction [4].

This study was based on the concept that in patients with $\mathrm{PE}$ the overgrowth of the costal cartilage could produce not only the inward bending of the sternum, but also longer cartilages than in normal subjects. Therefore, the aim was to compare the length of the costal cartilages of patients with PE versus normal subjects.

\section{Materials and Methods}

A total of 67 subjects were enrolled in this study. These included 32 patients with $\mathrm{PE}$ and 35 subjects without chest wall malformations that underwent a chest computed tomographic (CT) examination for other pathological conditions. The PE group consisted of 15 female and 17 male patients with an age range of 8-22 years. The mean age of the PE group was $14.82 \pm 3.93$ years. The control group consisted of 15 female and 20 male patients with an age range of $9-20$ years and mean age of $13.80 \pm 2.94$ years. All subjects were investigated prior to any surgical intervention. The CT scanning was performed with the patients in a supine position, during inspiration and without contrast enhancement. Either the Siemens SOMATOM Sensation 64 or Toshiba Aquilion CXL 64 machine was used. The images were acquired at a thickness of 0.5 $\mathrm{mm}$. The CT images were retrieved and analyzed using eFilm Lite v3.1.

On axial images the length of the 4th, 5th, 6th and 7th costal cartilages was measured (fig. 1a, b). Because 2D images were used, the length of the cartilages was considered from the costochondral junction to the edge of the sternum on the same side. On the same plane, at the level of the 5th costal cartilage, the transversal and the sagittal diameters were measured to calculate the Haller index. On the sagittal images, the height of the thorax was measured from the middle of the first thoracic vertebral body to the middle of the 12th thoracic vertebral body (fig. 1c). In order to surpass the variability related to normal anatomical and anthropometric individual differences, a process of normalization of the length of the costal cartilages was used. First, the median of the transverse and longitudinal diameters of the thorax was calculated for each subject. Then the measured length of the costal cartilages was divided by this
Table 1. Diameters of the thorax cavity

\begin{tabular}{lccl}
\hline & PE, $\mathrm{mm}$ & Controls, $\mathrm{mm}$ & $\mathrm{p}$ value \\
\hline Transverse & $233.29 \pm 24.47$ & $231.69 \pm 22.47$ & 0.816 \\
& $(183.50-265.50)$ & $(195.10-283.80)$ & \\
Coronal & $252.67 \pm 37.25$ & $238.64 \pm 27.40$ & 0.145 \\
& $(180.00-304.30)$ & $(196.1-282.90)$ & \\
Sagittal & $59.30 \pm 14.21$ & $95.40 \pm 19.59$ & 0.00 \\
& $(24.60-80.60)$ & $(53.8-126.6)$ & \\
Haller index & $4.20 \pm 1.34$ & $2.52 \pm 0.54$ & 0.00 \\
& $(3.23-8.46)$ & $(1.89-3.76)$ & \\
\hline
\end{tabular}

Values are the mean $\pm \mathrm{SD}$ with the range in parentheses.

median value. The formula used was: relative cartilage length $=$ actual cartilage length/(transverse diameter of the thorax + coronal diameter of the thorax)/2. The sagittal diameter was deliberately excluded because it is directly related to the disease. As this is not a standard technique, it was validated through the use of Pearson's correlation factor.

For the PE group, patients with asymmetric PE were selected and the length of the 4 th, 5 th, 6 th and 7 th costal cartilages between the rotated and nonrotated sides of the sternum was compared, while the symmetrical ones were assumed to be similar on both sides

\section{Statistical Analysis}

The unpaired test was used with a significance threshold set at $\mathrm{p}=0.05$ for $95 \% \mathrm{CI}$. To validate the process of normalization of the length of the costal cartilages, the correlation between cartilage length, thoracic diameters and the age, height and weight of the patients was calculated using Pearson's product-moment correlation coefficient.

\section{Results}

The age and gender distributions were similar in both groups with no significant differences $(\mathrm{p}=0.974$ and 0.307 , respectively). The mean height of the patients in 
Table 2. Pearson's product-moment correlation coefficients for the PE group

\begin{tabular}{|c|c|c|c|c|c|c|c|c|}
\hline & \multicolumn{2}{|l|}{ Age } & \multicolumn{2}{|l|}{ Weight } & \multicolumn{2}{|l|}{ Height } & \multicolumn{2}{|l|}{ Gender } \\
\hline & $\begin{array}{l}\text { correlation } \\
\text { coefficient }\end{array}$ & $\mathrm{p}$ value & $\begin{array}{l}\text { correlation } \\
\text { coefficient }\end{array}$ & $\mathrm{p}$ value & $\begin{array}{l}\text { correlation } \\
\text { coefficient }\end{array}$ & $\mathrm{p}$ value & $\begin{array}{l}\text { correlation } \\
\text { co-efficient }\end{array}$ & $\mathrm{p}$ value \\
\hline$\underline{\mathrm{DT}}$ & 0.701 & 0.000 & 0.781 & 0.000 & 0.777 & 0.000 & 0.150 & 0.474 \\
\hline$\overline{\mathrm{DS}}$ & 0.212 & 0.309 & 0.664 & 0.000 & 0.503 & 0.010 & 0.157 & 0.453 \\
\hline DC & 0.664 & 0.000 & 0.686 & 0.000 & 0.704 & 0.000 & 0.151 & 0.471 \\
\hline C4 left & 0.481 & 0.015 & 0.447 & 0.025 & 0.508 & 0.009 & 0.068 & 0.747 \\
\hline C4 right & 0.435 & 0.030 & 0.452 & 0.023 & 0.619 & 0.001 & 0.193 & 0.354 \\
\hline C5 left & 0.296 & 0.151 & 0.351 & 0.086 & 0.478 & 0.016 & 0.313 & 0.128 \\
\hline C5 right & 0.227 & 0.276 & 0.385 & 0.057 & 0.482 & 0.015 & 0.254 & 0.221 \\
\hline C6 left & 0.292 & 0.250 & 0.427 & 0.033 & 0.610 & 0.001 & 0.266 & 0.198 \\
\hline C6 right & 0.239 & 0.250 & 0.427 & 0.033 & 0.910 & 0.001 & 0.266 & 0.198 \\
\hline C7 left & 0.387 & 0.056 & 0.481 & 0.015 & 0.604 & 0.001 & 0.179 & 0.393 \\
\hline C7 right & 0.307 & 0.136 & 0.366 & 0.072 & 0.536 & 0.006 & 0.184 & 0.378 \\
\hline Haller & 0.046 & 0.829 & -0.050 & 0.813 & -0.153 & 0.465 & -0.064 & 0.761 \\
\hline R4 left & -0.184 & 0.480 & -0.234 & 0.261 & -0.213 & 0.307 & -0.031 & 0.883 \\
\hline R4 right & -0.81 & 0.699 & -0.125 & 0.553 & 0.081 & 0.699 & 0.135 & 0.521 \\
\hline R5 left & -0.215 & 0.301 & -0.225 & 0.279 & -0.085 & 0.685 & 0.235 & 0.259 \\
\hline R5 right & -0.279 & 0.176 & -0.184 & 0.377 & -0.081 & 0.699 & 0.224 & 0.281 \\
\hline R6 left & -0.301 & 0.144 & -0.258 & 0.213 & -0.123 & 0.559 & 0.224 & 0.281 \\
\hline R6 right & -0.376 & 0.064 & -0.232 & 0.264 & -0.021 & 0.921 & 0.179 & 0.392 \\
\hline R7 left & -0.246 & 0.236 & -0.212 & 0.310 & -0.068 & 0.745 & 0.072 & 0.734 \\
\hline R7 right & -0.300 & 0.145 & -0.302 & 0.142 & -0.103 & 0.626 & 0.088 & 0.675 \\
\hline
\end{tabular}

DT $=$ Transverse diameter of the thorax; DS = sagittal diameter of the thorax; $\mathrm{DC}=$ coronal diameter of the thorax; $\mathrm{C} \#=$ actual length of the costal cartilage; $\mathrm{R} \#=$ relative length of the costal cartilage.

the PE group was $160.73 \pm 22.82 \mathrm{~cm}$ (range 110-210) and in the control group was $153.96 \pm 13.56 \mathrm{~cm}$ (range 128178 ). The mean weight was $48.14 \pm 15.7 \mathrm{~kg}$ (range $25-88$ ) in the PE group and $49.4 \pm 13.86 \mathrm{~kg}$ (range 27-80) in the control group. There were significant differences between the groups for height and weight $(\mathrm{p}=0.209$ and 0.771 , respectively).

The mean of the transverse thoracic diameter was $233.29 \pm 24.47 \mathrm{~mm}$ for PE subjects and $231.69 \pm 22.47$ $\mathrm{mm}$ for the controls, while the mean coronal diameter was $252.67 \pm 37.25 \mathrm{~mm}$ for the PE group and $238.64 \pm$ $27.40 \mathrm{~mm}$ for the control group, with no statistical differences between them ( $p=0.816$ and 0.145 , respectively). The mean sagittal diameter in the PE group was $59.30 \pm$ $14.21 \mathrm{~mm}$, which was significantly lower than the $95.40 \pm$ $19.59 \mathrm{~mm}$ of the control group $(\mathrm{p}=0.00)$. A statistically significant difference was also found for the Haller index, which was $4.22 \pm 1.34$ for PE subjects and $2.52 \pm 0.54$ for the controls $(\mathrm{p}=0.00$; table 1$)$.

Pearson's product-moment correlation coefficients for each group are recorded in tables 2 and 3 . For the PE group we found linear correlations between all three tho- racic diameters with the height and weight of the patients. The measured lengths of the cartilages correlated with the height and weight of the patients (table 2). None the relative lengths of the costal cartilages correlated with the weight and height of the patients from the PE group ( $p>$ 0.05 ). The actual and relative lengths of the costal cartilages were similar between the PE subjects and controls for all 4 of the costal cartilages measured, as shown in table 4.

For the control group the transverse and coronal thoracic diameters correlated with the age, weight and height of the subjects, while the sagittal diameter correlated only with the height (table 3). The actual length of all costal cartilages correlated with the height of the subjects, while only the actual length of the 4th, 6th and 7th left cartilages correlated with the weight of the subjects from the control group. Regarding the age of the controls, only the actual length of the 5th cartilage of both sides revealed a linear correlation. None of the relative lengths of the costal cartilages correlated with age, height or weight ( $\mathrm{p}>$ 0.05). 
Table 3. Pearson's product-moment correlation coefficients for the control group

\begin{tabular}{|c|c|c|c|c|c|c|c|c|}
\hline & \multicolumn{2}{|l|}{ Age } & \multicolumn{2}{|l|}{ Weight } & \multicolumn{2}{|l|}{ Height } & \multicolumn{2}{|l|}{ Gender } \\
\hline & $\begin{array}{l}\text { correlation } \\
\text { coefficient }\end{array}$ & $\mathrm{p}$ value & $\begin{array}{l}\text { correlation } \\
\text { coefficient }\end{array}$ & $\mathrm{p}$ value & $\begin{array}{l}\text { correlation } \\
\text { coefficient }\end{array}$ & $\mathrm{p}$ value & $\begin{array}{l}\text { correlation } \\
\text { coefficient }\end{array}$ & $\mathrm{p}$ value \\
\hline DT & 0.651 & 0.001 & 0.786 & 0.000 & 0.798 & 0.000 & 0.271 & 0.223 \\
\hline DS & 0.124 & 0.124 & 0.461 & 0.031 & 0.469 & 0.028 & -0.001 & 0.998 \\
\hline $\mathrm{DC}$ & 0.740 & 0.000 & 0.891 & 0.000 & 0.845 & 0.000 & 0.128 & 0.569 \\
\hline C4 left & 0.295 & 0.183 & 0.591 & 0.004 & 0.535 & 0.010 & 0.430 & 0.042 \\
\hline C4 right & 0.295 & 0.150 & 0.438 & 0.042 & 0.475 & 0.025 & 0.422 & 0.050 \\
\hline C5 left & 0.318 & 0.033 & 0.583 & 0.004 & 0.490 & 0.021 & 0.500 & 0.018 \\
\hline C5 right & 0.455 & 0.033 & 0.613 & 0.002 & 0.547 & 0.008 & 0.315 & 0.153 \\
\hline C6 left & 0.359 & 0.101 & 0.574 & 0.005 & 0.519 & 0.013 & 0.689 & 0.000 \\
\hline C6 right & 0.237 & 0.288 & 0.485 & 0.022 & 0.434 & 0.044 & 0.528 & 0.012 \\
\hline C7 left & 0.355 & 0.105 & 0.563 & 0.006 & 0.602 & 0.003 & 0.468 & 0.028 \\
\hline C7 right & 0.231 & 0.300 & 0.438 & 0.041 & 0.445 & 0.038 & 0.295 & 0.183 \\
\hline Haller & -0.115 & 0.610 & -0.103 & 0.647 & -0.228 & 0.307 & 0.212 & 0.344 \\
\hline R4 left & -0.480 & 0.024 & -0.312 & 0.157 & -0.376 & 0.085 & 0.244 & 0.273 \\
\hline R4 right & -0.294 & 0.185 & -0.298 & 0.178 & -0.301 & 0.173 & 0.192 & 0.392 \\
\hline R5 left & -0.046 & 0.839 & -0.019 & 0.932 & -0.119 & 0.598 & 0.437 & 0.042 \\
\hline R5 right & -0.050 & 0.824 & -0.019 & 0.935 & -0.058 & 0.797 & 0.201 & 0.369 \\
\hline R6 left & -0.345 & 0.116 & -0.260 & 0.242 & -0.327 & 0.138 & 0.553 & 0.008 \\
\hline R6 right & -0.419 & 0.052 & -0.291 & 0.189 & -0.358 & 0.102 & 0.367 & 0.093 \\
\hline R7 left & -0.311 & 0.159 & -0.190 & 0.398 & -0.92 & 0.685 & 0.348 & 0.113 \\
\hline R7 right & -0.352 & 0.109 & -0.238 & 0.296 & -0.226 & 0.311 & 0.171 & 0.448 \\
\hline
\end{tabular}

$\mathrm{DT}=$ Transverse diameter of the thorax; DS = sagittal diameter of the thorax; $\mathrm{DC}=$ coronal diameter of the thorax; $\mathrm{C} \#=$ actual length of the costal cartilage; $\mathrm{R} \#=$ relative length of the costal cartilage.

Table 4. Absolute and relative lengths of the costal cartilages in PE subjects versus controls

\begin{tabular}{|c|c|c|c|c|c|}
\hline & \multicolumn{2}{|l|}{ PE subjects $(\mathrm{n}=32)$} & \multicolumn{2}{|l|}{ Controls $(\mathrm{n}=35)$} & $\mathrm{p}$ value \\
\hline \multirow[t]{2}{*}{ C4 left } & $46.41 \pm 6.00(37.30-58.90)$ & & $46.73 \pm 5.30(32.10-55.30)$ & & 0.850 \\
\hline & & $0.191 \pm 0.023(0.146-0.240)$ & & $0.200 \pm 0.023(0.159-0.256)$ & 0.239 \\
\hline \multirow[t]{2}{*}{ C4 right } & $46.63 \pm 6.73(34.0-62.60)$ & & $46.06 \pm 6.58(31.80-56.60)$ & & 0.772 \\
\hline & & $0.192 \pm 0.033(0.120-0.274)$ & & $0.195 \pm 0.021(0.157-0.234)$ & 0.686 \\
\hline \multirow[t]{2}{*}{ C5 right } & $64.14 \pm 12.90(45.80-90.00)$ & & $62.10 \pm 8.72(45.10-76.90)$ & & 0.524 \\
\hline & & $0.264 \pm 0.047(0.183-0.334)$ & & $0.264 \pm 0.035(0.190-0.334)$ & 0.964 \\
\hline \multirow[t]{2}{*}{ C6 left } & $76.13 \pm 10.78(59.90-100.50)$ & & $77.86 \pm 8.76(59.90-91.00)$ & & 0.566 \\
\hline & & $0.315 \pm 0.044(0.231-0.407)$ & & $0.331 \pm 0.038(0.245-0.441)$ & 0.192 \\
\hline \multirow[t]{2}{*}{ C6 right } & $75.01 \pm 11.13(54.50-99.40)$ & & $77.66 \pm 9.64(57.80-93.20)$ & & 0.387 \\
\hline & & $0.310 \pm 0.046(0.208-0.409)$ & & $0.330 \pm 0.035(0.270-0.417)$ & 0.112 \\
\hline
\end{tabular}

\footnotetext{
Values are the mean \pm SD with the range in parentheses.
} 
Table 5. Length of rotated costal cartilages compared to the nonrotated side

\begin{tabular}{|c|c|c|c|c|c|}
\hline & \multicolumn{2}{|l|}{ Rotated side } & \multicolumn{2}{|l|}{ Nonrotated side } & \multirow[t]{2}{*}{$\mathrm{p}$ value } \\
\hline & absolute length, mm & relative length, mm & absolute length, mm & relative length, $\mathrm{mm}$ & \\
\hline $\mathrm{C} 4$ & $46.20 \pm 7.25$ & $0.189 \pm 0.035$ & $48.00 \pm 6.73$ & $0.195 \pm 0.021$ & $\begin{array}{l}0.473 \\
0.581\end{array}$ \\
\hline C5 & $65.75 \pm 12.11$ & $0.267 \pm 0.042$ & $66.81 \pm 13.21$ & $0.271 \pm 0.045$ & $\begin{array}{l}0.814 \\
0.821\end{array}$ \\
\hline C6 & $74.33 \pm 11.17$ & $0.303 \pm 0.048$ & $76.06 \pm 11.77$ & $0.309 \pm 0.042$ & $\begin{array}{l}0.673 \\
0.716\end{array}$ \\
\hline C7 & $88.30 \pm 15.41$ & $0.360 \pm 0.053$ & $90.70 \pm 15.74$ & $0.368 \pm 0.045$ & $\begin{array}{l}0.665 \\
0.655\end{array}$ \\
\hline
\end{tabular}

The chest deformity was asymmetric in 23 patients with the sternum facing left in 16 and right in 7 patients. Of the 32 patients (96.9\%), 31 had a cup-shaped deformity and the remaining patient had a saucer-shaped deformity of the chest wall. Both the absolute and relative lengths of the costal cartilages on each side of the sternum were similar on the rotated and nonrotated sides (table 5).

\section{Discussion}

The results of this study did not reveal any difference between the length of the last 4 costal cartilages in patients with PE and normal subjects. Neither absolute nor the relative lengths of the cartilages were significantly different. Previous authors have postulated that the costal cartilage experiences an overgrowing pattern that is more pronounced during a child's period of rapid growth (growth spurt) $[1,2]$. The presumption is that costal cartilages are growing excessively compared to the rest of the rib cage, putting pressure on the sternum and forcing it to bend backward [3]. Based on this well-accepted concept we designed our study to look at costal cartilage dimensions to see if PE patients exhibit overgrowth when compared to their control counterparts. The present study found no such discrepancies, thus making the costal cartilages overgrowth theory very improbable [1]. Nakaoka et al. [5] compared the actual length and the cartilage/rib ratio of the 5th and 6th costal cartilages in PE patients with normal subjects. Like us, they found a similar length for the 5th costal cartilage on both sides, but found a shorter left 6th cartilage in PE patients compared to healthy controls. In our study, the only differences be-

Pectus Excavatum: Costal Cartilage Length tween the PE patients and controls were regarding the sagittal diameter of the thorax and the Haller index. Similar results were published for patients with pectus carinatum deformity of the anterior chest wall $[6,7]$.

The correlation between the thoracic diameters and the absolute length of the costal cartilages with the age, height and weight of the subjects revealed that all of them increase linearly in both PE and non-PE subjects. On the other hand, the relative length of the costal cartilages does not correlate with the age, height or weight of the patients, indicating that we have successfully eliminated these constitutional variables from comparison through the normalization process. It is well known that in PE patients both the structure and the length of the adjacent rib may be affected $[8,9]$. For this reason we preferred to report the actual length of the cartilages to the mean of the transverse and coronal diameters of the rib cage. In this way we could compare the lengths of the cartilages considering simultaneously the individual constitutional factors.

We further compared the length of the costal cartilages between the rotated and nonrotated side in asymmetric PE patients. The results showed no difference between the lengths of the 4 th, 5th, 6 th and 7 th cartilages on each side of the sternum. This was a predictable outcome considering that the lengths were the results of the comparison between PE and normal subjects. We therefore disagree with Nakaoka et al. [10], who found differences between the lengths of the 5th and 6th costal cartilages from the rotated and nonrotated sides of asymmetric pectus deformity patients. The fact that they included only 12 patients in their study may be an important source for error. On the other hand, the comparison between the lengths of cartilages between the sides of the 
sternum may be irrelevant, even in patients with an asymmetric deformity of the anterior chest wall. This is why we considered that the only relevant approach was to compare the length of the costal cartilages between patients with $\mathrm{PE}$ and patients with no deformity of the chest wall.

\section{Conclusion}

The lengths of 4th, 5th, 6th and 7th costal cartilages were similar in PE patients and normal subjects. These were also similar between the rotated and nonrotated sides of the sternum in patients with asymmetric PE. Thus, these findings could indicate that costal cartilage overgrowth cannot be a main causative factor for PE.

\section{References}

1 Sweet RH: Pectus excavatum. Ann Surg 1944; 119:922-934.

-2 Kelly RE Jr: Pectus excavatum: historical background, clinical picture, preoperative evaluation and criteria for operation. Semin Pediatr Surg 2008;17:181-193.

3 Fokin AA, Steuerwald NM, Ahrens WA, et al: Anatomical, histologic, and genetic characteristics of congenital chest wall deformities. Semin Thorac Cardiovasc Surg 2009;21:4457.

-4 Feng J, Hu T, Liu W, et al: The biomechanical, morphologic, and histochemical properties of the costal cartilages in children with pectus excavatum. J Pediatr Surg 2001;36:1770-1776.
Nakaoka T, Uemura S, Yoshida T, et al: Overgrowth of costal cartilage is not the etiology of pectus excavatum. J Pediatr Surg 2010;45: 2015-2018.

6 Park CH, Kim TH, Haam SJ, et al: The etiology of pectus carinatum involves overgrowth of costal cartilage and undergrowth of ribs. J Pediatr Surg 2014;49:1252-1258.

$\checkmark 7$ Park CH, Kim TH, Haam SJ, et al: Does overgrowth of costal cartilage cause pectus carinatum? A three-dimensional computed tomography evaluation of rib length and costal cartilage length in patients with asymmetric pectus carinatum. Interact Cardiovasc Thorac Surg 2013;17:757-763.
8 Benhamed L, Hysi I, Wurtz AJ: eComment: is overgrowth of costal cartilages the unique cause of pectus deformities? Interact Cardiovasc Thorac Surg 2013;17:763.

9 Cubuk S, Yucel O: eComment: dilemma of the costal cartilage overgrowth in chest wall deformities. Interact Cardiovasc Thorac Surg 2013; 17:763.

10 Nakaoka T, Uemura S, Yano T, et al: Does overgrowth of costal cartilage cause pectus excavatum? A study on the lengths of ribs and costal cartilages in asymmetric patients. J Pediatr Surg 2009 ;44:1333-1336. 